\title{
Ages of hepatocellular carcinoma occurrence and life expectancy are associated with a UGT2B28 genomic variation
}

Puo-Hsien Le ${ }^{1,2}$, Chia-Jung Kuo ${ }^{2}$, Yi-Chung Hsieh², Tsung-Hsing Chen ${ }^{2}$, Chih-Lang Lin ${ }^{1,3,4}$, Chau-Ting Yeh ${ }^{1,2,4^{*}}$ and Kung-Hao Liang ${ }^{5,6,7^{*}}$ (D)

\begin{abstract}
Background: Hepatocellular carcinoma (HCC) is an aggressive solid tumor. HCC occurred at younger and elder ages were considered driven by different oncogenic mechanisms, and they demonstrated distinct clinical courses.

Methods: A total of 382 HCC patients treated by surgical resections was analyzed.

Results: A univariate-multivariate analysis showed that viral etiology (chronic hepatitis $B, C$ ) and the UDP glucuronosyltransferase family 2 member B28 (UGT2B28) genomic variant rs2132039 were independently associated with the age at presentation of HCC (all adjusted $P<0.05$ ). An extensive evaluations of clinicalpathological factors showed that the age (Odds ratio [OR], 1.016; 95\% confidence interval [Cl], 1.001-1.032; adjusted $P=0.037$ ) and ascites $(\mathrm{OR}, 3.505 ; \mathrm{Cl}, 1.358-9.048$; adjusted $P=0.010)$ were two independent factors associated with this genomic variant. The age was $54.1 \pm 14.6$ years for patients with the "TT" variant type, and $58.2 \pm 13.7$ years for those with the "Non-T" variant type. The age disparity was most prominent in alcoholic patients (OR, 1.079; $\mathrm{Cl}, 1.035-1.125 ; P<$ 0.001 , age of "TT", $49.6 \pm 12.2$; age of "non- $T$ ", $59.3 \pm 10.7)$. This genomic variant was also associated with age of recurrence $(P=0.025)$, distant metastasis $(P=0.024)$ and HCC-related death $(P=0.008)$ in non-censored patients.
\end{abstract}

Conclusions: An UGT2B28 genomic variant was indicative of the age of HCC presentation, recurrence, distant metastasis and death.

Keywords: Young hepatocellular carcinoma; age of death, Xenobiotic metabolizing enzymes, Alcoholism

\section{Background}

Hepatocellular carcinoma (HCC) is a prevalent malignancy with an age-standardized rates of 10.1 per 100 , 000 person-years in the world [1]. Patients diagnosed as early stages of HCC can be treated by curative methods such as surgical resection and liver transplantation [2, 3]. In contrast, patients in advanced stages were either due to delayed diagnosis, or failure of previous treatments. They can only be treated by palliative methods [2, 3]. Early hepatocellular

\footnotetext{
*Correspondence: chautingy@gmail.com; kunghao@gmail.com

'Liver Research Center, Linkou Chang Gung Memorial Hospital, 5, Fu-Shin

street, Kuei-Shan District, Taoyuan, Taiwan

${ }^{5}$ Department of Medical Research, Taipei Veterans General Hospital, Taipei, Taiwan

Full list of author information is available at the end of the article
}

carcinoma (HCC) often lacks overt clinical symptoms [4], therefore, susceptible patients need to schedule regular surveillance ahead of time. Ultrasound and the alpha-fetoprotein levels are important surveillance tools which have demonstrated their effectiveness in enabling early $\mathrm{HCC}$ detection and in increasing life expectancy [3, 5-8]. However, the ages of HCC presentation is not homogeneous in different patient subgroups. Therefore, biomarkers indicating the starting ages of surveillance would have great clinical values. HCC occurred at younger and elder ages have been thought to have distinct oncogenic mechanisms [9] and possibly subsequent clinical course [10]. It was currently unknown how the age at presentation was related to genetics, despite the observation that 


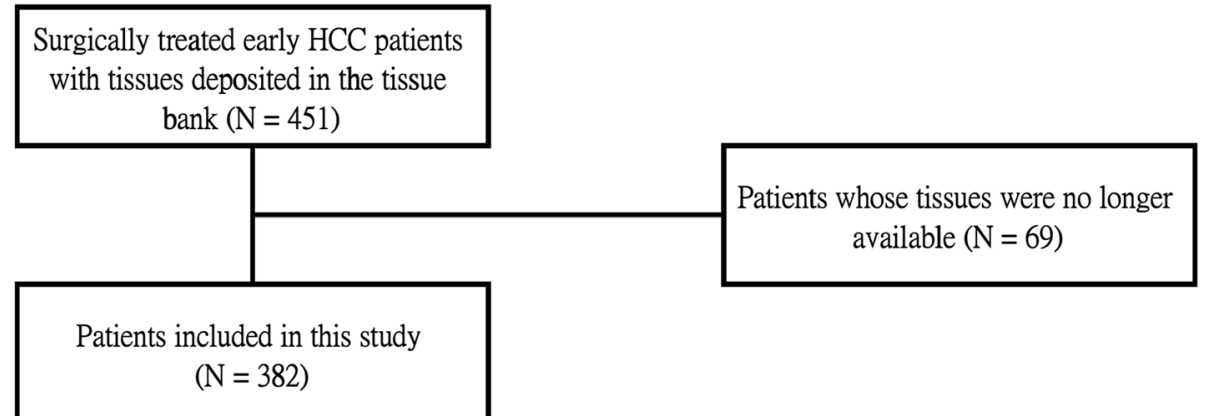

Fig. 1 The flowchart of patient enrollment in this study

different ethnic groups have different age of presentation [3].

Alcoholism, as well as the hepatitis $\mathrm{B}$ and $\mathrm{C}$ viral infections (HBV and $\mathrm{HCV}$ ), are the major etiologies of HCC [11-19]. Treatments of viral infections have improve significantly in recent years. In chronic hepatitis B patients, the risk of HCC is positively related to serum HBV DNA levels [11, 20], and both of them can be substantially reduced by anti-HBV therapy [21, $22]$. Besides, nationwide hepatitis $B$ vaccination program has reduced HBV carrier rate significantly in Taiwan, a former HBV endemic region [23]. HCV infection is also one important etiology of HCC particularly in western countries [24]. Direct-acting antivirals can achieve $100 \%$ sustained virologic response rate [25-28], thereby reducing the risk of HCC [29]. As a result, alcohol-related HCC are more and more important, due to the reduction of relative importance of other etiologies.

The UDP glucuronosyltransferase family 2 member B28 (UGT2B28) gene encodes an important xenobiotic metabolizing enzyme abundantly expressed in the human liver and kidney, and are responsible for the metabolisms of bile acids and sex hormones [3033]. The copy number variations of $U G T 2 B 28$ are associated with the risks of prostate cancers, esophageal squamous cell cancers, and colorectal cancers [34-37]. The genomic variant UGT2B28-rs2132039 and an adjacent copy number variation CNP605 have recently been reported to be associated with the natural history of chronic hepatitis $\mathrm{B}$, particularly the e-antigen seroconversion [38]. The two adjacent genomic variants were surrogates of each other [38]. However, the role of $U G T 2 B 28$ in the clinical course of liver diseases, particularly the occurrence of HCC, has not been studied to date. Thus, we investigated the relationship between UGT2B28-rs2132039 genomic variant and the clinicopathological features, particularly the age at presentation in early $\mathrm{HCC}$ patients.
Table 1 Baseline characteristics of 382 HCC patients in this study

\begin{tabular}{|c|c|}
\hline Characteristic & Values \\
\hline Gender, male, $n(\%)$ & $295(77.2 \%)$ \\
\hline Age at diagnosis, years, median (range) & $58.0(19.0-87.0)$ \\
\hline Tumor number, median (range) & $1.0(1.0-10.0)$ \\
\hline Capsule, $n(\%)$ & $280(73.3 \%)$ \\
\hline Tumor grade, median (range) & $3.0(1.0-4.0)$ \\
\hline Macrovascular invasion, $n$ (\%) & $41(10.7 \%)$ \\
\hline Microvascular invasion, $n$ (\%) & $121(31.7 \%)$ \\
\hline Tumor size, cm, median (range) & $4.3(0.7-20.0)$ \\
\hline Cirrhosis, n (\%) & $225(58.9 \%)$ \\
\hline Ascites, n (\%) & $26(6.8 \%)$ \\
\hline HBV alone, $n(\%)$ & $228(59.7 \%)$ \\
\hline HCV alone, $n(\%)$ & $63(16.5 \%)$ \\
\hline $\mathrm{HBV}+\mathrm{HCV}, n(\%)$ & $36(9.4 \%)$ \\
\hline NBNC, n (\%) & 55 (14.4\%) \\
\hline Alcoholism (\%) & 97 (25.4\%) \\
\hline UGT2B28 rs2132039 T, n (\%) & $181(47.4 \%)$ \\
\hline UGT2B28 rs2132039 Non-TT, n (\%) & $201(52.6 \%)$ \\
\hline Prothrombin time, second, median (rang) & $11.9(9.0-19.5)$ \\
\hline AST, U/L, median (range) & $37.0(11.0-559.0)$ \\
\hline ALT, U/L, median (range) & $39.0(7.0-749.0)$ \\
\hline Bilirubin, mg/dL, median (range) & $0.8(0.3-15.3)$ \\
\hline Albumin, g/dL, median (range) & $4.1(1.7-5.1)$ \\
\hline Creatinine, mg/dL, median (range) & $1.0(0.4-15.4)$ \\
\hline Alpha-fetoprotein, ng/mL, median (range) & $26.5(1.0-685,353.0)$ \\
\hline Recurrent, $n(\%)$ & $212(55.5 \%)$ \\
\hline Recurrent time, month, median (range) & $12.9(1.0-114.7)$ \\
\hline Metastasis, $n(\%)$ & $73(19.1 \%)$ \\
\hline Metastatic time, month, median (range) & $13.0(1.0-99.2)$ \\
\hline Death, $n(\%)$ & $47(12.3 \%)$ \\
\hline Survival time, month, median (range) & $22.5(0.1-73.7)$ \\
\hline
\end{tabular}

Abbreviations: $H B V$ Hepatitis B virus carrier, $H C V$ Hepatitis $C$ virus carrier, $H B V+$ HCV Co-infection of hepatitis B virus and hepatitis C virus, NBNC Non-hepatitis $B /$ hepatitis $C$ virus carrier, AST Aspartate aminotransferase, ALT Alanine aminotransferase 


\section{Methods}

\section{Patients}

A screening in the tissue bank of the Chang Gung Memorial Hospital, Linko, Taiwan, identified 451 early HCC patients who have their surgical tissues deposited. Among them, the tissues of 69 patients were no longer available. The remaining $382 \mathrm{HCC}$ patients were then included in this study (Fig. 1). Most tumor characteristics of patients included and not included in this study were similar, except tumor sizes (Additional file 4: Table $\mathrm{S} 1)$. After the genomic variants were detected from the non-tumor part of the 382 surgical tissues, relevant clinical data were retrospectively retrieved from the clinical charts, including the ages at the diagnosis of HCC, gender, liver cirrhosis, ascites, alcoholism (defined by an average alcohol consumption $>210 \mathrm{~g}$ per week in males or $>140$ per week in females over at least a 2-year period with physical or psychological dependence), HBV surface antigen (HBsAg), antibody to $\mathrm{HCV}$ (anti-HCV), prothrombin time (PT), aspartate transaminase (AST), alanine transaminase (ALT), bilirubin, albumin, creatinine, $\alpha$-fetoprotein (AFP), tumor size, tumor number, capsule, tumor grade, macrovascular invasion and microvascular invasion. Patients with both $\mathrm{HBsAg}$ positivity and antibody anti-HCV positivity were considered as coinfection. We also analyzed the subsequent clinical events after the surgery, including local recurrence, distant metastasis and death, for a follow-up period of $49.2 \pm 30.8$ months.

\section{Genotyping of genomic variant}

Fresh-frozen surgical tissues were thawed, and then the total DNA was extracted from the non-tumor part of these samples. The polymerase chain reaction method was then used for amplifying the DNA carrying the
UDP glucuronosyltransferase family 2 member B28 (UGT2B28) rs2132039 genomic variant using the primers 5'-GAGGCTCCATCATAGTCTGGC-3' and 5'-TTGCCTGGCTTCTCATTGTT-3'. The amplicon sequence was shown in Additional file 1: Figure S1. Conventional Sanger sequencing was then performed, and the base-calling was done on the sequencing trace files using the public-domain novoSNP bioinformatics tool [39]. Ambiguous calls which cannot be classified by the software were called by human curators.

\section{Statistical analysis}

Categorical variables were summarized as absolute numbers and percentages, and compared using the Chisquared test. Continuous variables were summarized as median and range, and compared using Mann-Whitney test, or two-sample t-test with unequal variance. Univariate and multivariate analyses were performed by either linear, logistic or Cox regression. The results were shown as odd ratios (OR), hazard ratios (HR), 95\% confidence interval $(\mathrm{CI})$ and $P$ values. The results were considered to indicate a statistically significant difference when $\mathrm{P}$ was less than 0.05 . All statistical calculations were performed using SPSS software, version 21 (IBM, Armonk, NY, USA).

\section{Results}

Evaluating clinical factors associated with age of HCC presentation

Table 1 summarizes the clinical variables of the patients included. The median age at HCC diagnosis was 58 years. The male to female ratio was 3.39. A total of 181 (47.4\%) patients had the rs2132039-“TT" variant type, while $201(52.6 \%)$ patients had the "Non-TT" variant

Table 2 Univariate and multivariate linear regression analysis of clinical factors associated to the age at diagnosis

\begin{tabular}{|c|c|c|c|c|c|c|c|c|}
\hline & \multicolumn{4}{|c|}{ Univariate Analysis } & \multicolumn{4}{|c|}{ Multivariate Analysis } \\
\hline & slope & Cl-low & Cl-high & $P$ & slope & Cl-low & Cl-high & $P$ \\
\hline Gender, male & -2.468 & -5.884 & 0.947 & 0.156 & & & & \\
\hline \multicolumn{9}{|l|}{ Etiology } \\
\hline B & -10.083 & -13.02 & -7.146 & $<0.001^{*}$ & -7.292 & -10.453 & -4.132 & $<0.001^{*}$ \\
\hline C & 10.061 & 6.944 & 13.177 & $<0.001^{*}$ & 6.415 & 3.064 & 9.766 & $<0.001^{*}$ \\
\hline Alcoholism & -2.482 & -5.772 & 0.808 & 0.139 & & & & \\
\hline Cirrhosis & 1.149 & -1.768 & 4.065 & 0.439 & & & & \\
\hline Ascites & 0.193 & -5.51 & 5.895 & 0.947 & & & & \\
\hline AST, U/L & -0.014 & -0.036 & 0.007 & 0.194 & & & & \\
\hline $\mathrm{ALT}, \mathrm{U} / \mathrm{L}$ & -0.016 & -0.034 & 0.002 & 0.089 & & & & \\
\hline Tumor size, cm & -0.240 & -0.602 & 0.122 & 0.193 & & & & \\
\hline \multicolumn{9}{|c|}{ UGT2B28 rs2132039 } \\
\hline$\pi$ & -4.106 & -6.952 & -1.26 & $0.005^{*}$ & -2.842 & -5.52 & -0.164 & $0.038^{*}$ \\
\hline
\end{tabular}


type (Table 1). We first asked which clinical factors were associated with the age of $\mathrm{HCC}$ presentation. It was found that viral etiology (chronic hepatitis $B, C$ ) and the UGT2B28 rs2132039 genomic variant were independently associated with the age (all adjusted $P<0.05$, Table 2).

The fact that the genomic variant was associated with the age, independent of viral etiology, was particularly interesting. Therefore, we examined an extensive list of clinicalpathological variables for their associations with the genomic variant. The "TT" and "non-TT" counts does not have significant difference between cirrhotic and non-cirrhotic patients $(P=0.307)$. The univariate logistic regression analysis showed that age (OR 1.021, 95\% C.I. 1.006-1.036, $P=0.005$ ), ascites (OR 3.223, 95\% C.I. $1.264-8.215, P=0.014)$ and hepatitis $C$ infection (OR 1.839, 95\% C.I. 1.148-2.945, $P=0.011$ ) were associated with the genomic variant (Table 3). Multivariate analysis revealed that age (OR 1.016, 95\% C.I. 1.001$1.032, P=0.037$ ) and ascites (OR 3.505, 95\% C.I. 1.358$9.048, P=0.010)$ were independently associated with the variant type (Table 3 ).

Subgroup analysis was then performed to further evaluate the relationship between the genomic variant and the age. It showed that the genomic variant was most tightly associated with age in alcoholic patients (OR 1.079, 95\% C.I. 1.035-1.125, $P<0.001$ ) (Fig. 2). A large effect size was observed that the age distributions were $59.3 \pm 10.7$ and $49.6 \pm 12.2$ years old in patients with "Non-TT" and "TT" variant types, respectively (Fig. 3a). The area under the receiver operating characteristic curve (AUC) was $71.6 \%$ when the genomic variant was classified by age (Fig. 3b). Apart from alcoholism, highly significant associations were also found in the subgroups of patients with AST $>37 \mathrm{U} / \mathrm{L}$ (OR 1.038, 95\% C.I. 1.015-1.063, $P=$ 0.001 ) and bilirubin $>0.8 \mathrm{mg} / \mathrm{dL}$ (OR 1.042, 95\% C.I. 1.017-1.068, $P=0.001$, Fig. 2).

Similarly, the variant-ascites and variant-HCV associations in various subgroup was shown in Additional file 2: Figure S2 and Additional file 3: Figure S3.

\section{UGT2B28 genomic variant was associated with age of recurrence, metastasis and death in non-censored patients}

We then analyzed the subsequent clinical events after surgery, including local recurrence, distant metastasis and death in non-censored patients. Patients of the "TT" variant type had a younger age of recurrence (55.8 \pm 14.6, $N=96)$ than those of the "Non-TT" variant type (60.3 $\pm 13.8, N=116, P=0.025$, Fig. 4). Also, patients of the "TT" variant type had a younger age of distant metastasis $(52.3 \pm 15.0, N=40)$ than those of the "Non-TT" variant type $(60.0 \pm 13.4, N=33, P=0.024)$. Among all
Table 3 Extensive evaluations of associations between the clinicopathological variables and the UGT2B28-rs2132039 variant types (i.e. the dependent variable, $\Pi=0$, Non- $\Pi=1$ ) using univariate and multivariate logistic regression analysis

\begin{tabular}{|c|c|c|c|}
\hline Characteristic & Odds ratio & $95 \% \mathrm{Cl}$ & $P$-value \\
\hline \multicolumn{4}{|l|}{ Univariate analysis } \\
\hline Gender, male & 0.824 & $0.509-1.334$ & 0.431 \\
\hline Age at diagnosis, years & 1.021 & $1.006-1.036$ & $0.005^{*}$ \\
\hline Tumor size, cm & 0.981 & $0.932-1.032$ & 0.449 \\
\hline Tumor number & 1.084 & $0.886-1.328$ & 0.432 \\
\hline Capsule & 1.094 & $0.695-1.721$ & 0.699 \\
\hline Tumor grade & 0.940 & $0.698-1.266$ & 0.685 \\
\hline Macrovascular invasion & 0.842 & $0.440-1.610$ & 0.603 \\
\hline Microvascular invasion & 0.760 & $0.493-1.170$ & 0.212 \\
\hline Cirrhosis & 1.072 & $0.713-1.613$ & 0.737 \\
\hline Ascites & 3.223 & $1.264-8.215$ & $0.014^{*}$ \\
\hline Alcoholism & 0.845 & $0.533-1.340$ & 0.475 \\
\hline HBV & 0.710 & $0.458-1.101$ & 0.126 \\
\hline $\mathrm{HCV}$ & 1.839 & $1.148-2.945$ & $0.011^{*}$ \\
\hline $\mathrm{HBV}+\mathrm{HCV}$ & 1.291 & $0.644-2.588$ & 0.471 \\
\hline NBNC & 0.848 & $0.479-1.502$ & 0.572 \\
\hline Prothrombin time, second & 0.938 & $0.811-1.084$ & 0.385 \\
\hline AST, U/L & 1.002 & $0.999-1.005$ & 0.246 \\
\hline $\mathrm{ALT}, \mathrm{U} / \mathrm{L}$ & 1.003 & $1.000-1.005$ & 0.095 \\
\hline Bilirubin, mg/dL & 0.960 & $0.808-1.142$ & 0.646 \\
\hline Albumin, g/dL & 0.820 & $0.572-1.175$ & 0.279 \\
\hline Creatinine, mg/dL & 0.976 & $0.790-1.206$ & 0.823 \\
\hline Alpha-fetoprotein, $\mathrm{ng} / \mathrm{mL}$ & 1.000 & $1.000-1.000$ & 0.377 \\
\hline Recurrent & 1.208 & $0.806-1.811$ & 0.359 \\
\hline Recurrent time, month & 0.995 & $0.988-1.001$ & 0.113 \\
\hline Metastasis & 0.692 & $0.415-1.156$ & 0.160 \\
\hline Metastatic time, month & 0.998 & $0.991-1.004$ & 0.435 \\
\hline Death & 0.767 & $0.416-1.414$ & 0.395 \\
\hline Survival time, month & 0.998 & $0.992-1.005$ & 0.632 \\
\hline \multicolumn{4}{|l|}{ Multivariate analysis } \\
\hline Age, years & 1.016 & $1.001-1.032$ & $0.037^{*}$ \\
\hline Ascites & 3.505 & $1.358-9.048$ & $0.010^{*}$ \\
\hline $\mathrm{HCV}$ & 1.646 & $0.999-2.713$ & 0.050 \\
\hline
\end{tabular}

Abbreviations: $\mathrm{Cl}$ Confidence interval, $\mathrm{HBV}$ Hepatitis $\mathrm{B}$ virus carrier, $\mathrm{HCV}$ Hepatitis $C$ virus carrier, $H B V+H C V$ Co-infection of hepatitis $B$ virus and hepatitis $C$ virus, NBNC Non-hepatitis B/hepatitis C virus carrier, AST Aspartate aminotransferase, $A L T$ Alanine aminotransferase

${ }^{*} P<0.05$ were indicated as bold face with an asterisk

patients, a total of 47 patients have complete follow-up information until death. Patients of the "TT" variant type had a significantly younger age of HCC-related death $(52.2 \pm 17.1, N=25)$ than those of the "Non-TT" variant type $(63.7 \pm 11.0, N=22, P=0.008)$. 


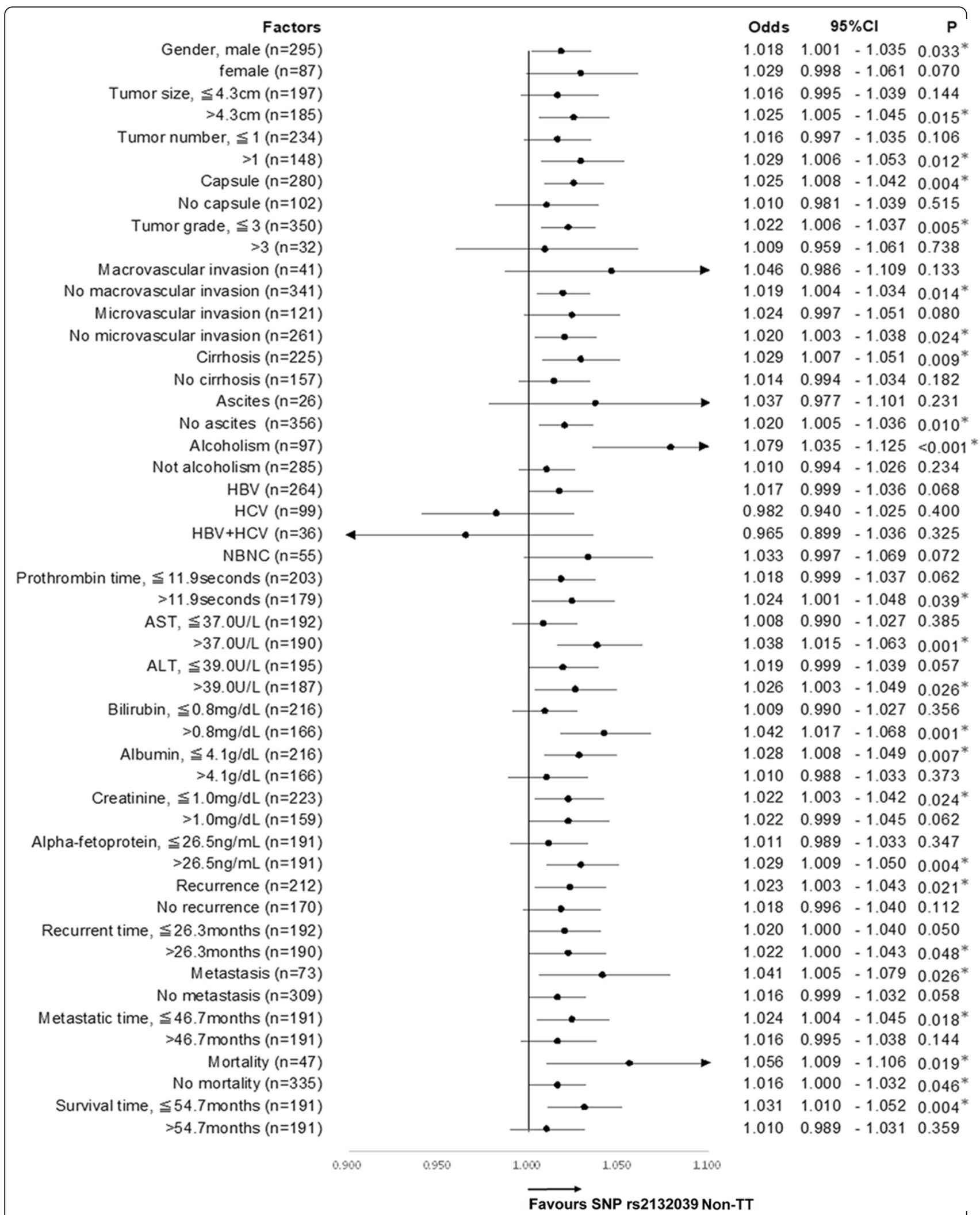

Fig. 2 The forest plot of associations between the rs2132039 genomic variant and the age of HCC diagnosis in subgroups of patients stratified by extensive clinicopathological parameters. ${ }^{*}$ indicates a statistically significant association when $P<0.05$ 
A.

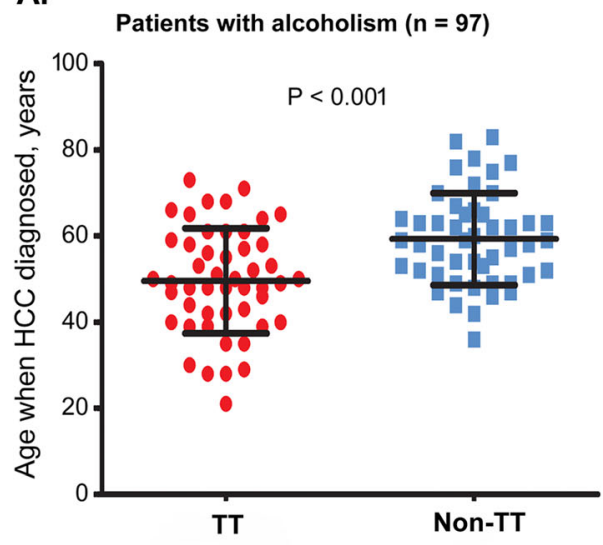

B.

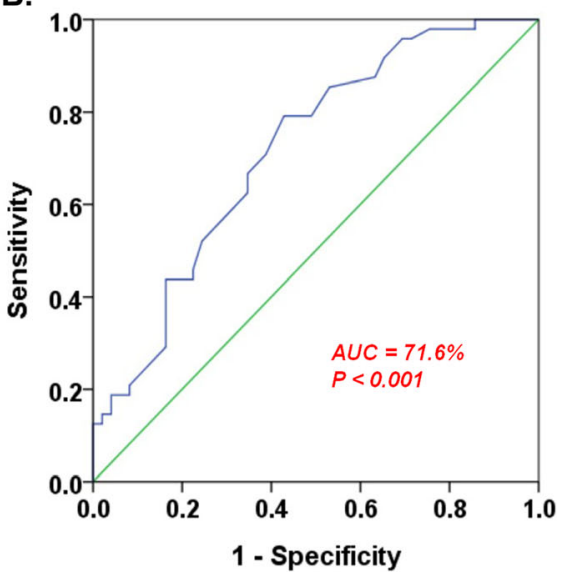

Fig. 3 a The distribution of age of HCC diagnosis in the subgroup of patients with alcoholism. Red and blue dots represent the patients with rs2132039- "TT" variant type and "Non-TT" variant type respectively. The age of "TT", $49.6 \pm 12.2$; the age of "non- $T$ ", $59.3 \pm 10.7$ ( $P<0.001)$. $\mathbf{b}$ Receiver operating characteristic curve of the classification of rs2132039 genomic variant using ages. AUC, area under curve

We also analyzed censored and non-censored data jointly. The UGT2B28-rs2132039-variant type was not associated with post-surgery time to recurrence, time to distant metastasis and death. However, among various subgroups (Additional file 5: Table S2), it was found that the "Non-TT" variant type was associated with higher cumulative incidence of recurrence in the patients with tumor size $\leqq 4.3 \mathrm{~cm}$ (HR 1.568, 95\% CI $1.061-2.315, \quad P=0.024)$ and $\mathrm{AFP} \leqq 26.5 \mathrm{ng} / \mathrm{mL} \quad(\mathrm{HR}$ 1.623; $95 \%$ CI $1.067-2.469, P=0.024$ ). The "Non-TT" variant type was associated with lower cumulative incidence of distant metastasis in the patients with tumor grade $\leqq 3$ (HR 0.599, 95\% CI $0.367-0.979, P=$ 0.041), microvascular invasion (HR $0.500,95 \%$ CI $0.257-0.975, P=0.042)$ and AFP $>26.5 \mathrm{ng} / \mathrm{mL}$ (HR 0.538 ; $95 \%$ CI $0.296-0.979, P=0.043)$. The "Non-TT" variant type was associated with lower cumulative incidence of death in the patients with ascites (HR $0.058,95 \%$ CI $0.006-0.523, P=0.011)$ and albu$\min \leqq 4.1 \mathrm{~g} / \mathrm{dL} \quad(\mathrm{HR} \quad 0.414 ; \quad 95 \%$ CI $0.197-0.870, \quad P=$ 0.020). The corresponding Kaplan-Meier plots of these subgroups of patients were shown in Fig. 5.

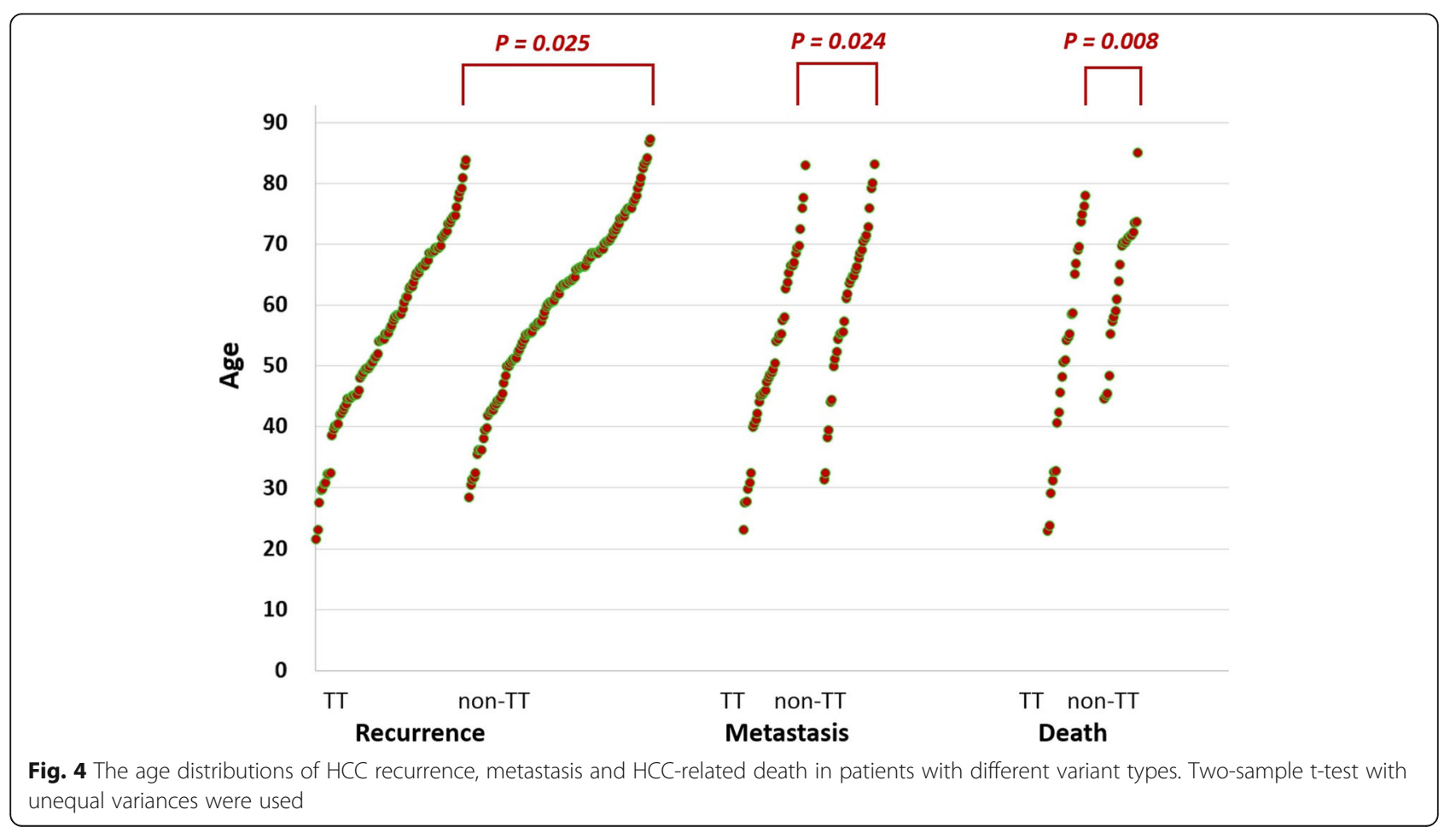



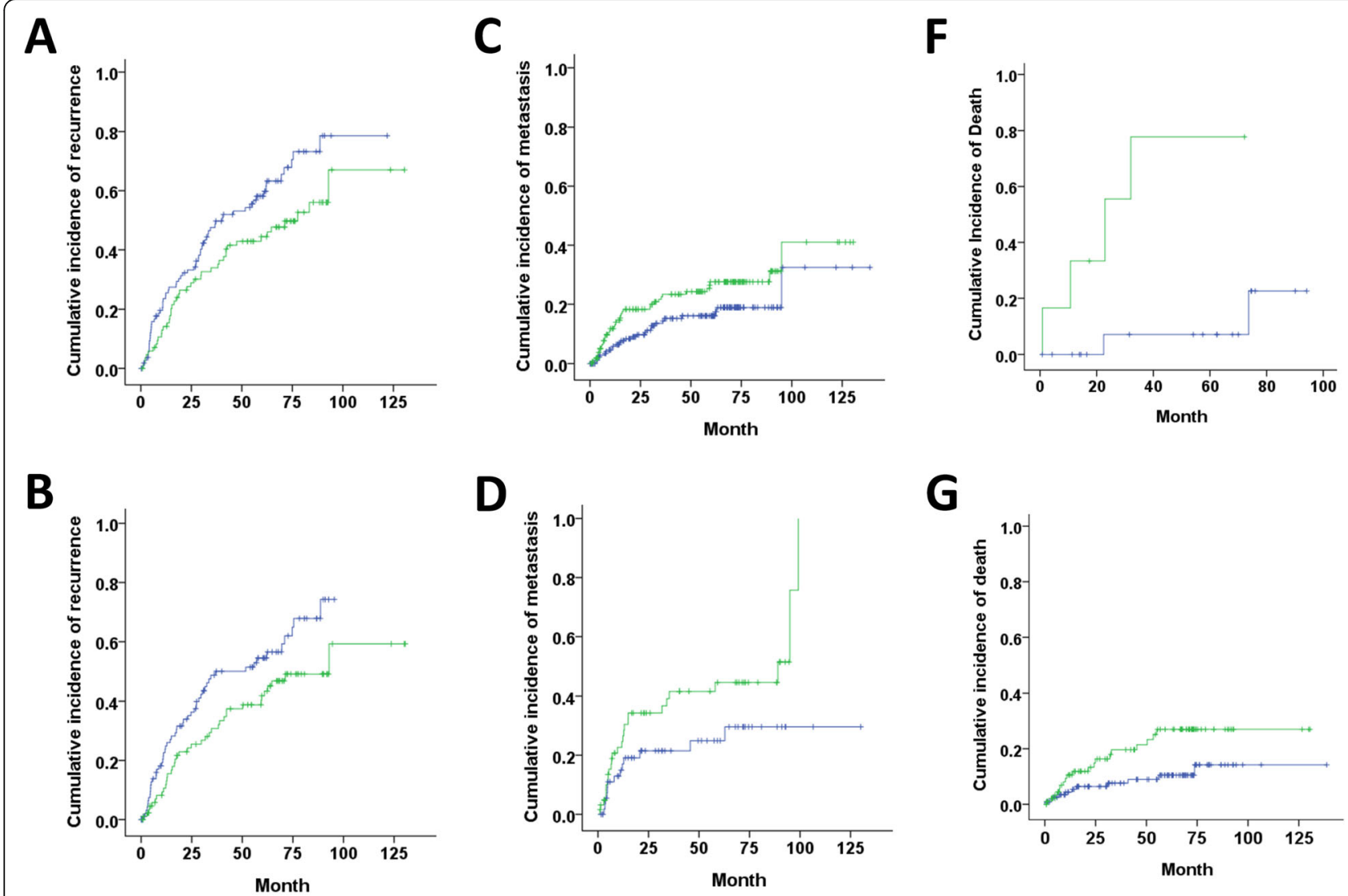

D

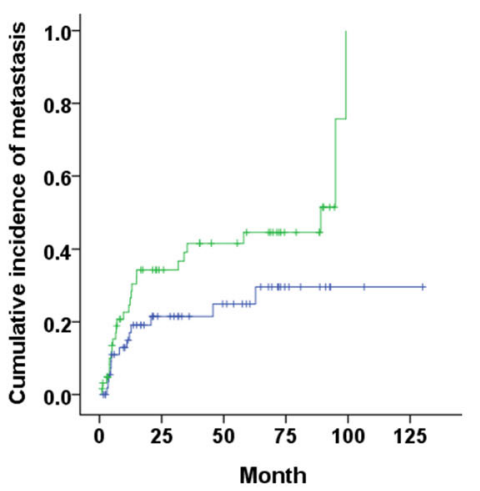

$\mathbf{E}$

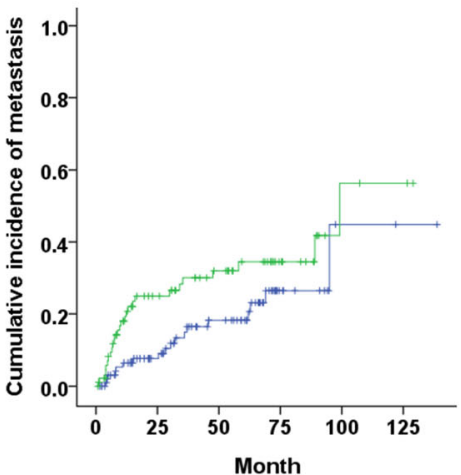

G

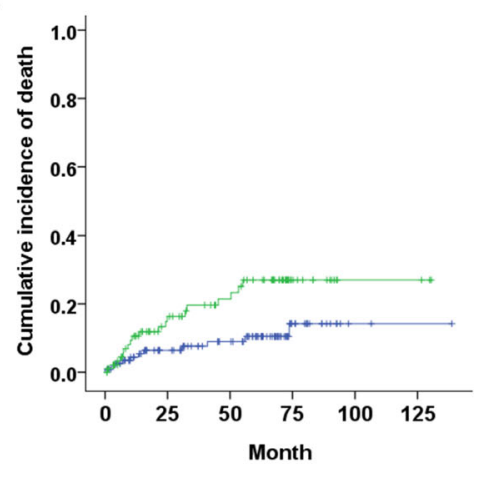

Fig. 5 The Kaplan-Meier plots for the cumulative incidence of recurrence in patients of (a) smaller tumor size ( $\leqq 4.3 \mathrm{~cm})$ and (b) lower AFP level $(\leqq 26.5 \mathrm{ng} / \mathrm{mL})$; for metastasis in patients of (c) lower tumor grade ( $\leqq 3)$, (d) microvascular invasion and (e) higher AFP level $(>26.5 \mathrm{ng} / \mathrm{mL})$; for death in patients with $(\mathbf{f})$ ascites and $(\mathbf{g})$ lower albumin level $(\leqq 4.1 \mathrm{~g} / \mathrm{dL})$. Green: patients with the variant type "TT"; Blue: patients with the variant type "Non-TT"

\section{Discussion}

In this study, we only analyzed patients in early HCC stages in the tissue bank, because those in advanced stages were either due to failure of previous treatments (such as surgical resections) or delayed diagnosis. For those with delayed diagnosis, the length of delay was not homogeneous in different people. One major goal of this study was to estimate the age of HCC presentation as early as possible, for the purpose of improving surveillance. The patients with delayed diagnosis may introduce uncontrolled variability to this study. Hence, we screened the tissue bank and identified 382 surgically treated HCC patients whose deposited tissues were available for this study, and other 69 patients whose tissues were no longer available. Clearly, the currently study was limited by the sample availability. A 
comparison of tumor characteristics showed that most tumor characteristics were similar, except tumor size (Additional file 4: Table S1). The tissue bank supported a wide diversity of clinical investigations, such as the immunohistochemical staining which usually requires tissues with decent sizes [40]. In our data, the tumor size does not associated with the age of presentation (Table 2) and the genomic variant (Table 3). Hence, we assumed the exclusion of the 69 patients did not affect greatly the conclusions of this research.

The investigated genomic biomarker was significantly associated with the ages of HCC presentation, recurrence, distant metastasis and death. We conducted a scrutiny of the post-surgery clinical outcomes. The age disparity of the two variant types showed stronger statistical significance in death ages $(P=0.008, N=47)$ than in recurrence ages $(P=0.025, N=212$, Fig. 4), despite the sample size was smaller. To explore the genomic effect in detail, we conducted an extensive subgroup analysis and discovered that (1) in the patients of smaller tumor size and lower AFP level, "Non-TT" variant type had higher cumulative incidence of recurrence; (2) in the patients of lower tumor grade, microvascular invasion and higher AFP level, "Non-TT" variant type had lower cumulative incidence of metastasis; (3) in the patients with ascites and lower albumin level (usually advanced cirrhosis), "Non-TT" variant type had lower cumulative incidence of death (Fig. 5). These observations could be generalized that the "Non-TT" variant type indicates better survival, compared with "TT" variant type, in the patients with more advanced HCC (ascites, lower albumin level, microvascular invasion and higher AFP level). The protective effect of "NonTT" variant in subgroups of patients may contribute toward the more prominent difference in the age distribution of death.

The UGT2B28 gene encodes a phase-two xenobiotic metabolizing enzyme which can transfer glucuronic acid from uridine diphosphoglucuronic acid to substrates such as bile acids, 5-beta-androstane 3-alpha, 17-betadiol, estradiol, androsterone, eugenol [30-32], steroid hormones and lipid-soluble drugs [41]. Its role in bile acid metabolism may explain why the association was more prominent in patients with bilirubin $>0.8 \mathrm{mg} / \mathrm{dL}$, and patients with heavy alcohol consumption.

This study was limited by the lack of serum aflatoxin levels, a known liver toxin which has been shown to shorten the time of HCC occurrence in Taiwan and worldwide [42]. Aflatoxin was not routinely measured in patients with chronic liver disease in Taiwan, particularly when the patients already have disease-causing etiology identified such as viral infections and heavy alcohol consumptions. The quantitative aflatoxin measurements were largely missing in the clinical charts and thus were not analyzed.

\section{Conclusion}

Patients with UGT2B28-rs2132039 - TT variant type had an earlier presentation of HCC, earlier post-surgery recurrence, metastasis and HCC-related death. The mean age difference of HCC presentation was particularly large ( 10 years) in alcoholic patients. Such information is helpful for formulating an effective surveillance strategy.

\section{Supplementary information}

Supplementary information accompanies this paper at https://doi.org/10. 1186/s12885-019-6409-3.

Additional file 1: Figure S1. The theoretical amplicon sequence based on the human reference genome GRCh38.p7.

Additional file 2: Figure S2. The forest plot of odds ratios of the rs2132039 genomic variant with respect to ascites in subgroups of patients stratified by clinicopathological parameters. * indicates a statistically significant association when $P<0.05$

Additional file 3: Figure S3. The forest plot of odds ratios of the rs2132039 genomic variant with respect to HCV infections in subgroups of patients stratified by clinicopathological parameters. * indicates a statistically significant association when $P<0.05$.

Additional file 4: Table S1. Tumor characteristics of patients who have deposited their surgical tissues in the tissue bank.

Additional file 5: Table S2. The univariate Cox regression analysis of subsequent events after the curative resection in various subgroups $($ Non- $T$ T $=1, T=0)$

\section{Abbreviations}

ALT: Alanine aminotransferase; AST: Aspartate aminotransferase;

$\mathrm{Cl}$ : Confidence interval; HBV: Hepatitis B virus carrier; HCC: Hepatocellular carcinoma; HCV: Hepatitis C virus; HR: Hazard ratio; NBNC: Non-hepatitis B/ hepatitis $C$

\section{Acknowledgements}

The authors would like to thank Dr. Tong-Hong Wang for his assistance in handling tissue bank samples, as well as Yi-Ting Liao and Yi-Wen Li for the excellent technical and administrative assistance.

\section{Authors' contributions}

C-TY designed the study, supervised the study and critically reviewed the manuscript. P-HL, C-JK, Y-CH, T-HC, C-LL, and C-TY. were involved in the data interpretation and clinical supervision of the patients. P-HL, K-HL and C-TY analyzed the data and wrote the manuscript. All authors approved the final version of the manuscript.

\section{Funding}

This work was supported by grants from the Ministry of Science and Technology, Taiwan (MOST-106-2314-B-075-074-MY2) for study design, data interpretation and manuscript writing, as well as the Chang Gung Memorial Hospital (CMRPG3E0241, CMRPG2B0463 and CLRPG3C0012) for sample processing and data collection.

Availability of data and materials

De-linked data are available to academic scientists upon request.

\section{Ethics approval and consent to participate}

This study was conducted under the approval of Institutional Review Board, Chang Gung Memorial Hospital, and performed in accordance of the Declaration of Helsinki ethical principles on human studies. All enrolled patients have given written informed consent. 


\section{Consent for publication}

Not applicable.

\section{Competing interests}

The authors declare that they have no competing interests.

\section{Author details}

'Liver Research Center, Linkou Chang Gung Memorial Hospital, 5, Fu-Shin street, Kuei-Shan District, Taoyuan, Taiwan. ${ }^{2}$ Department of Gastroenterology and Hepatology, Linkou Chang Gung Memorial Hospital, Taoyuan, Taiwan. ${ }^{3}$ Liver Research Unit, Keelung Chang Gung Memorial Hospital, Keelung, Taiwan. ${ }^{4}$ College of Medicine, Chang Gung University, Taoyuan, Taiwan. ${ }^{5}$ Department of Medical Research, Taipei Veterans General Hospital, Taipei, Taiwan. ${ }^{6}$ Institute of Food Safety and Health Risk Assessment, National Yang-Ming University, Taipei, Taiwan. ${ }^{7}$ Institute of Biomedical Informatics, National Yang-Ming University, Taipei, Taiwan.

\section{Received: 9 April 2019 Accepted: 28 November 2019}

\section{Published online: 05 December 2019}

\section{References}

1. Ferlay J, Soerjomataram I, Dikshit R, Eser S, Mathers C, Rebelo M, Parkin DM, Forman D, Bray F. Cancer incidence and mortality worldwide: sources, methods and major patterns in GLOBOCAN 2012. Int J Cancer. 2014;136(5): E359-86.

2. Bruix J, Sherman M. Management of hepatocellular carcinoma. Hepatology. 2005;42(5):1208-36.

3. Marrero JA, Kulik LM, Sirlin CB, Zhu AX, Finn RS, Abecassis MM, Roberts LR, Heimbach JK. Diagnosis, staging, and Management of Hepatocellular Carcinoma: 2018 practice guidance by the American Association for the Study of Liver Diseases. Clin Liver Dis. 2019;13(1):1-1.

4. Kew MC, Dos Santos HA, Sherlock S. Diagnosis of primary cancer of the liver. Br Med J. 1971:4(5784):408-11.

5. Zhang BH, Yang BH, Tang ZY. Randomized controlled trial of screening for hepatocellular carcinoma. J Cancer Res Clin Oncol. 2004;130(7):417-22.

6. Singal AG, Pillai A, Tiro J. Early detection, curative treatment, and survival rates for hepatocellular carcinoma surveillance in patients with cirrhosis: a meta-analysis. PLoS Med. 2014;11(4):e1001624.

7. Singal AG, Mittal S, Yerokun OA, Ahn C, Marrero JA, Yopp AC, Parikh ND, Scaglione SJ. Hepatocellular Carcinoma Screening Associated with Early Tumor Detection and Improved Survival Among Patients with Cirrhosis in the US. Am J Med. 2017;130(9):1099-106 e1091.

8. Harris PS, Hansen RM, Gray ME, Massoud OI, McGuire BM, Shoreibah MG. Hepatocellular carcinoma surveillance: An evidence-based approach. World J Gastroenterol. 2019;25(13):1550-9.

9. Wang H-W, Hsieh T-H, Huang S-Y, Chau G-Y, Tung C-Y, Su C-W, Wu J-C. Forfeited hepatogenesis program and increased embryonic stem cell traits in young hepatocellular carcinoma (HCC) comparing to elderly HCC. BMC Genomics. 2013;14(1):736.

10. Chen C-H, Chang T-T, Cheng K-S, Su W-W, Yang S-S, Lin HH, Wu S-S, Lee CM, Changchien C-S, Chen C-J, et al. Do young hepatocellular carcinoma patients have worse prognosis? The paradox of age as a prognostic factor in the survival of hepatocellular carcinoma patients. Liver Int. 2006;26(7): 766-73.

11. Beasley RP, Hwang LY, Lin CC, Chien CS. Hepatocellular carcinoma and hepatitis B virus. A prospective study of 22707 men in Taiwan. Lancet. 1981;2(8256):1129-33.

12. Bruix J, Barrera JM, Calvet X, Ercilla G, Costa J, Sanchez-Tapias JM, Ventura M, Vall M, Bruguera M, Bru C, et al. Prevalence of antibodies to hepatitis C virus in Spanish patients with hepatocellular carcinoma and hepatic cirrhosis. Lancet. 1989;2(8670):1004-6.

13. Colombo M, Kuo G, Choo QL, Donato MF, Del Ninno E, Tommasini MA, Dioguardi N, Houghton M. Prevalence of antibodies to hepatitis C virus in Italian patients with hepatocellular carcinoma. Lancet. 1989;2(8670):1006-8.

14. Davila JA, Morgan RO, Shaib Y, McGlynn KA, El-Serag HB. Hepatitis C infection and the increasing incidence of hepatocellular carcinoma: a population-based study. Gastroenterology. 2004;127(5):1372-80.

15. Trichopoulos D, Bamia C, Lagiou P, Fedirko V, Trepo E, Jenab M, Pischon T, Nothlings U, Overved K, Tjonneland A, et al. Hepatocellular carcinoma risk factors and disease burden in a European cohort: a nested case-control study. J Natl Cancer Inst. 2011;103(22):1686-95.
16. Mayans MV, Calvet X, Bruix J, Bruguera M, Costa J, Esteve J, Bosch FX, Bru C, Rodes J. Risk factors for hepatocellular carcinoma in Catalonia, Spain. Int J Cancer. 1990;46(3):378-81.

17. Donato F, Tagger A, Gelatti U, Parrinello G, Boffetta P, Albertini A, Decarli A, Trevisi P, Ribero ML, Martelli C, et al. Alcohol and hepatocellular carcinoma: the effect of lifetime intake and hepatitis virus infections in men and women. Am J Epidemiol. 2002;155(4):323-31.

18. Chiesa R, Donato F, Tagger A, Favret M, Ribero ML, Nardi G, Gelatti U, Bucella E, Tomasi E, Portolani N, et al. Etiology of hepatocellular carcinoma in Italian patients with and without cirrhosis. Cancer Epidemiol Biomark Prev. 2000:9(2):213-6.

19. Ganne-Carrié N, Nahon P. Hepatocellular carcinoma in the setting of alcohol-related liver disease. J Hepatol. 2019;70(2):284-93.

20. Chen CJ, Yang HI, Su J, Jen CL, You SL, Lu SN, Huang GT, lloeje UH. Risk of hepatocellular carcinoma across a biological gradient of serum hepatitis $B$ virus DNA level. Jama. 2006;295(1):65-73.

21. Hosaka T, Suzuki F, Kobayashi M, Seko Y, Kawamura Y, Sezaki H, Akuta N, Suzuki Y, Saitoh S, Arase $Y$, et al. Long-term entecavir treatment reduces hepatocellular carcinoma incidence in patients with hepatitis B virus infection. Hepatology. 2013;58(1):98-107.

22. Liaw YF. HBeAg seroconversion as an important end point in the treatment of chronic hepatitis B. Hepatol Int. 2009;3(3):425-33.

23. Ni YH, Chen DS. Hepatitis B vaccination in children: the Taiwan experience. Pathologie-biologie. 2010;58(4):296-300.

24. Lee MH, Yang HI, Lu SN, Jen CL, You SL, Wang LY, L'Italien G, Chen CJ, Yuan $Y$. Hepatitis $C$ virus genotype $1 \mathrm{~b}$ increases cumulative lifetime risk of hepatocellular carcinoma. Int J Cancer. 2014;135(5):1119-26.

25. Chae HB, Park SM, Youn SJ. Direct-acting antivirals for the treatment of chronic hepatitis C: open issues and future perspectives. Sci World J. 2013; 2013:704912.

26. Keating GM. Ledipasvir/Sofosbuvir: a review of its use in chronic hepatitis C. Drugs. 2015;75(6):675-85.

27. Zeuzem S, Foster GR, Wang S, Asatryan A, Gane E, Feld JJ, Asselah T, Bourliere M, Ruane PJ, Wedemeyer $\mathrm{H}$, et al. Glecaprevir-Pibrentasvir for 8 or 12 weeks in HCV genotype 1 or 3 infection. N Engl J Med. 2018;378(4):354-69.

28. Andreone P, Colombo MG, Enejosa JV, Koksal I, Ferenci P, Maieron A, Mullhaupt B, Horsmans Y, Weiland O, Reesink HW, et al. ABT-450, ritonavir, ombitasvir, and dasabuvir achieves 97 and 100\% sustained virologic response with or without ribavirin in treatment-experienced patients with HCV genotype 1b infection. Gastroenterology. 2014;147(2):359-65 e351.

29. Pinero F, Mendizabal M, Ridruejo E, Herz Wolff F, Ameigeiras B, Anders M, Schinoni Ml, Reggiardo V, Palazzo A, Videla M, et al. Treatment with directacting antivirals for HCV decreases but does not eliminate the risk of hepatocellular carcinoma. Liver Int. 2019:39(6):1033-43.

30. Guillemette C. Pharmacogenomics of human UDP-glucuronosyltransferase enzymes. Pharm J. 2003;3(3):136-58.

31. Guillemette $C$, Levesque $E$, Rouleau M. Pharmacogenomics of human uridine diphospho-glucuronosyltransferases and clinical implications. Clin Pharmacol Ther. 2014:96(3):324-39.

32. Belledant $A$, Hovington $H$, Garcia L, Caron $P$, Brisson $H$, Villeneuve $L$, Simonyan D, Tetu B, Fradet Y, Lacombe L, et al. The UGT2B28 sex-steroid inactivation pathway is a regulator of Steroidogenesis and modifies the risk of prostate Cancer progression. Eur Urol. 2016;69(4):601-9.

33. Montella M, D'Arena G, Crispo A, Capunzo M, Nocerino F, Grimaldi M, Barbieri A, D'Ursi AM, Tecce MF, Amore A, et al. Role of sex hormones in the development and progression of hepatitis B virus-associated hepatocellular carcinoma. Int J Endocrinol. 2015;2015:854530.

34. Angstadt AY, Berg A, Zhu J, Miller P, Hartman TJ, Lesko SM, Muscat JE, Lazarus P, Gallagher CJ. The effect of copy number variation in the phase II detoxification genes UGT2B17 and UGT2B28 on colorectal cancer risk. Cancer. 2013;119(13):2477-85.

35. Hu L, Wu Y, Guan X, Liang Y, Yao X, Tan D, Bai Y, Xiong G, Yang K. Germline copy number loss of UGT2B28 and gain of PLEC contribute to increased human esophageal squamous cell carcinoma risk in Southwest China. Am J Cancer Res. 2015;5(10):3056-71.

36. Habibi M, Mirfakhraie R, Khani M, Rakhshan A, Azargashb E, Pouresmaeili F. Genetic variations in UGT2B28, UGT2B17, UGT2B15 genes and the risk of prostate cancer: a case-control study. Gene. 2017;634:47-52.

37. du Toit T, Swart AC. Perspective on the regulatory role of UGT2B28 as a conjugating enzyme in the progression of prostate cancer. Transl Cancer Res. 2016;5(S7):S1496-502. 
38. Liang KH, Lin CL, Hsu CW, Lai MW, Chien RN, Yeh CT. UGT2B28 genomic variation is associated with hepatitis $\mathrm{B}$ e-antigen seroconversion in response to antiviral therapy. Sci Rep. 2016;6:34088.

39. Weckx S. novoSNP, a novel computational tool for sequence variation discovery. Genome Res. 2005;15(3):436-42.

40. Liang K-H, Lin C-L, Chen S-F, Chiu C-W, Yang P-C, Chang M-L, Lin C-C, Sung $K-F$, Yeh C, Hung C-F, et al. GALNT14 genotype effectively predicts the therapeutic response in unresectable hepatocellular carcinoma treated with transcatheter arterial chemoembolization. Pharmacogenomics. 2016;17(4): 353-66.

41. Levesque E, Turgeon D, Carrier JS, Montminy V, Beaulieu M, Belanger A. Isolation and characterization of the UGT2B28 CDNA encoding a novel human steroid conjugating UDP-glucuronosyltransferase. Biochemistry. 2001;40(13):3869-81.

42. Chu Y-J, Yang H-I, Wu H-C, Liu J, Wang L-Y, Lu S-N, Lee M-H, Jen C-L, You S$L$, Santella RM, et al. Aflatoxin Blexposure increases the risk of cirrhosis and hepatocellular carcinoma in chronic hepatitis B virus carriers. Int I Cancer. 2017;141(4):711-20.

\section{Publisher's Note}

Springer Nature remains neutral with regard to jurisdictional claims in published maps and institutional affiliations.

Ready to submit your research? Choose BMC and benefit from:

- fast, convenient online submission

- thorough peer review by experienced researchers in your field

- rapid publication on acceptance

- support for research data, including large and complex data types

- gold Open Access which fosters wider collaboration and increased citations

- maximum visibility for your research: over $100 \mathrm{M}$ website views per year

At BMC, research is always in progress.

Learn more biomedcentral.com/submissions 